\title{
Editorial: Introduction to Issue 8(3)
}

\author{
SIMON DAWES, Université Paul Valéry, Montpellier, France
}

This is the editorial introduction to the first ever standard issue of Networking Knowledge Journal of the MeCCSA-PGN. In contrast to the usual run of guest-edited themed issues, interspersed with an issue, published at the beginning of every year, dedicated to the best of the papers given at the previous MeCCSA-PGN Annual Conference, this issue features articles on unrelated themes, as well as reports on conferences and publishing initiatives. While the authors come from a diverse range of disciplinary backgrounds (such as law, philosophy, sociology, journalism studies), the articles and reports cover topics that will interest many researchers working within the interdisciplinary fields of media, communication and cultural studies.

From theoretical articles drawing on the work of Gilbert Simondon and Jacques Rancière, to empirical articles on the portrayal of women in World Wrestling Entertainment programming and discourse analyses of newspaper coverage of Roman Polanski's 2009 arrest, the range of topics covered is wide. The issue also features reports on recent conferences on Scotland, human rights, and creative research methods, as well as a report on a new initiative to translate English-language communication books into Turkish.

The issue begins with Yuk Hui's densely theoretical article on media aesthetics and digital objects, 'Induction, Deduction and Transduction: On the Aesthetics and Logic of Digital Objects'. Arguing that the neuro-turn and the computational turn in cultural analysis requires us to return to philosophical questions concerning the mind and spirit, Hui attempts to reconnect philosophical inquiries with the current search for a digital aesthetics. After outlining particular philosophical approaches to aesthetics, and defining digital objects as a new form of industrial objects, composed of conceptualized or structural data and metadata, he goes on to develop a new framework for analysing media aesthetics. He begins with an account of induction in the British empiricist tradition, particularly in the work of David Hume - whereby rules are derived from facts - and of deduction, particularly the transcendental deduction of Immanuel Kant - whereby rules are followed in order to 
understand the foundation of knowledge - to argue that they don't necessarily oppose each other, but serve rather as the foundation of a 'transcendental empiricism'. Hui criticises the inability of the dominant approaches to fully account for digital objects, and argues for the need to grasp the transcendental without losing the empirical, and to firmly ground the psycho-social affects produced by media technologies in their technical reality. The new framework he proposes - of transduction - draws in particular on Gilbert Simondon's theory of individuation, and allows the identification of a common ground between machine and human that is shared by both philosophical and technological lines of thinking.

In Samuel Burgum's contribution, 'Rancière and Occupy (in) London: An Interview with A.N.Onymous', the author develops an earlier interview with a political activist into a reflection on the ways in which the theory of Jacques Rancière can be drawn upon to understand and critique Occupy London. The article proposes links between the protesters' tactic of occupying space and Rancière's theory of power via the policing of aesthetic appearances. It also draws parallels between the contradictions of unequal power and authority among the Occupy protesters in London (an inner circle of 'experts' and the others), and Rancière's critique of Althusser's contradictory politics around the May '68 events in Paris (refusing to support the protesters, in spite of his claim to represent the emancipation of the masses). As well as applying Rancière to Occupy, however, Burgum also draws on the experiences of the activist to critique contradictions in some of Rancière's theories. Ultimately, he demonstrates how the split between the 'settlement' and the 'movement' of Occupy - the 'hardware' and the 'software'; the 'camps' and the 'meetings', the 'offline' and the 'online' - appeared to play out alongside the unequal subject positions of the protesters. While the middle-class 'experts' emphasised the movement and established a hierarchy of knowledge and power, the 'ground troops', made up of the homeless, newly arrived immigrants, alcoholics, drug addicts and the mentally ill, remained committed to the occupation of space. The author concludes by emphasising the importance of avoiding both romanticism and cynicism in critiquing Occupy, and of critiquing 'naively' from within, rather than from a position of academic expertise and authority.

Carrie Dunn's 'Sexy, Smart and Powerful': Examining Gender and Reality in the WWE Divas' Division', examines the portrayal of women in 'sports entertainment', particularly in the scripted worlds of both the wrestling ring and associated reality TV programming. Dunn deconstructs the celebrity of wrestling 'divas', arguing that to be 'successful' and guarantee 
web hits and column inches, a diva must be sexy, smart and powerful, and she examines how each of these qualities are described and portrayed in WWE programming. Her article interrogates the reduction of women's wrestling in World Wrestling Entertainment programming to just filler material between the more important men's wrestling, tactics of 'slut-shaming' and the construction of women as promiscuous and crazy, and the removal of women from the ring to the realm of reality television. In doing so, it touches on issues of masculinity and femininity, the representation of women and the performance of gender in sport and television, hyperreality and the blurring of the boundaries between reality and fiction, as well as fame and celebrity.

In the final full-length article in the issue, Julia Lefkowitz's 'A Comparative Approach to a Transatlantic Scandal: Le Monde and the New York Times' Coverage of Roman Polanski's 2009 Arrest' connects the press coverage of this particular event to a range of political, social, and moral issues. The article also connects the differences in French and American press coverage to differences between French and American national ideologies. In applying a Critical Discourse Analysis (CDA) approach, Lefkowitz focuses in particular on the construction of the artist's worth and perceptions of sexual misconduct. She contrasts the liberal privileging of Puritan and pragmatic priorities in the American press with the republican privileging of humanism and aesthetics in the French media, before explaining some of the legislative differences between the two countries; contrasting the presumption of innocence and protection of privacy of those accused of crimes in France, with the perp walks of suspects in the States. The author also interprets some of the French media reaction to the arrest warrant of a French citizen, who is also a famous and respected artist, as a defence of French culture and as opposition to the pervasiveness of American culture.

As well as these peer-reviewed articles, this issue also features a selection of conference and publishing reports. The first report comes from Robert Munro, who presents the 'Becoming Scotland: Screen Cultures in a Small Nation' conference, which was held at the end of August last year at Queen Margaret University. The conference provided a unique opportunity for those interested in the future, past and present of screen culture in Scotland to gather less than a month before Scotland voted on its referendum on independence. It offered a wide variety of perspectives, including those of professional filmmakers and producers, and its aim was to stimulate debate at such a crucial juncture in Scotland's history, and in some instances look to the future and ask what it would hold for screen production in Scotland. 
Bethany Rodgers then reports on the 'Human Rights in the UK Media: Representation and Reality' conference that took place last September at the University of Liverpool Law School. At the time of writing this introduction and publishing this issue, the newly elected Conservative government have put the issue of human rights, and the associated issue of the future of UK-EU relations, firmly back on the political agenda, and this conference was organised in anticipation of this 'looming battle over rights'. The conference touched upon the mistakes, misconceptions and misrepresentations of human rights in UK media, particularly the issues of erroneous reporting, and the disproportionate focus on 'undeserving' human rights claims in certain newspapers. However, some participants also acknowledged the need to debate rights, and emphasised the importance of constructing a constitutional debate on what role human rights (should) play within the UK.

Poppy Wilde and Francien Broekhuizen then report on the 'Workshop on Creative Methods: Gender, Sex and Relating', which was held at Coventry University last October. The workshop can be located within a broader interest in the cultural and social sciences into alternative and creative ways of research practice to capture the complexity of life in more diverse and multiple layered ways than traditional methods that privilege objectivity, stable sites, and "facts". Through tactile engagement with dolls, for instance, participants could engage with the research topic in different ways, capture feelings in more complex ways, and develop alternative ways of reflecting upon their own research practice. The main focus of this workshop was exploring how creative methods can push the boundaries of research and research practice to create more space for consciousness raising and reflection.

Last but not least, the issue ends with a report from Ahmet Faruk Cecen on his experience of working among a group of young academics in Turkey who have established their own book series. The Communication Book Series (Altinbilek Publishing House) seeks, primarily, to translate English-language books on media, communication and cultural studies into Turkish (though it also now plans to start publishing original works in Turkish). Faruk Cecen discusses some of the issues with translating communication concepts from English to Turkish, the state of Turkish communication studies and the kind of books they're busy translating. 
Publishing such an issue has given these authors the opportunity to publish work in their respective areas, which otherwise would only have been possible in this journal if they had spoken at the Annual Conference, or if their topic corresponded to that of a newly published call for papers for a forthcoming special issue. The inclusion of reports has also meant that the journal can better perform its role as a hub of information on recent developments in media, communication and cultural studies fields.

I look forward to the next such issue.

Simon Dawes is the editor of Networking Knowledge - Journal of the MeCCSA-PGN. He did his $\mathrm{PhD}$ at Nottingham Trent University, and currently teaches at Université Paul Valéry, Montpellier, France. His research revolves around issues of media regulation, history and theory.

Email: simondawes0@gmail.com

Website: http://smdawes.wordpress.com/ 